\title{
The absolute number of nerve cells in substantia nigra in normal subjects and in patients with Parkinson's disease estimated with an unbiased stereological method
}

\author{
B Pakkenberg, A Møller, H J G Gundersen, A Mouritzen Dam, H Pakkenberg
}

\begin{abstract}
Using an unbiased stereological technique, the total numbers of pigmented and non-pigmented neurons were estimated in the substantia nigra of seven patients with Parkinson's disease and seven control patients. Compared with the controls, in which the average total number of pigmented neurons was 550000 , the number of neurons was reduced by $66 \%$ in the patients. The average total number of non-pigmented neurons was 260000 in controls and reduced by $24 \%$ in the patients. A significant correlation $(r=0.81)$ existed between the total numbers of pigmented and non-pigmented neurons in the controls, whereas a similar correlation $(\mathbf{r}=\mathbf{0 . 7 2})$ in the patients fell just short of statistical significance. The stereological estimates made in this study are unbiased, in that they are independent of nerve cell size, section thickness and of dimensional changes in brain tissue induced by histological procedures. The stereological method is considerably more efficient than previous conventional methods.
\end{abstract}

A reduced number of pigmented neurons in the substantia nigra ( $\mathrm{SN}$ ) has been reported in patients with Parkinson's disease ${ }^{1-5}$ and since then this part of the human brain has been of great interest in the research of Parkinson's disease. Cell counts in SN were carried out in 1965 by Pakkenberg and Brody ${ }^{6}$ who found the average pigmented and non-pigmented neuron profile number in one mid section through the $\mathrm{SN}$ to be reduced by approximately $65 \%$. Using a similar conventional, and biased, counting method, McGeer et al ${ }^{7}$ found the relative cell number of pigmented neurons in the $S N$ in four patients with Parkinson's disease to be reduced to about $31 \%$ of controls. In none of these patients did the estimated total number of pigmented neurons exceed 140000 . Others have reported the reduction of neuron numbers to be approximately $80 \%$ in the $\mathrm{SN}$ in patients with Parkinson's disease. ${ }^{8}$

The aim of this study was to estimate the total numbers of pigmented and nonpigmented neurons in the substantia nigra of patients with Parkinson's disease and to compare this number with that of a control group.
The total number of pigmented and non-pigmented cells was estimated with the disector, an unbiased stereological procedure for direct estimation of the number of arbitrarily shaped cells. ${ }^{9}$ In addition to being unbiased, the method is far more efficient than earlier conventional methods. For a recent review of this and other new stereological procedures, see Gundersen et al..$^{10}$

\section{Material}

Seven brains from patients with Parkinson's disease were sex- and age-matched with those of seven controls who had not shown signs of neurological disorder or dementia. The diagnosis was confirmed by the obvious effect of DOPA-treatment. Information about the age, sex, duration of disease, and causes of death for the patients in the two groups are shown in table 1. Exclusion criteria common to the two groups were primary and secondary tumours, infection of the CNS, or a history of alcohol or drug abuse. Also excluded were brains from patients who had been comatose for more than 24 hours before death and those not removed within 72 hours of death. All brains were analysed blindly by one investigator.

\section{Method}

The upper brainstem was sliced at $5 \mathrm{~mm}$ in a plane that was transverse to the longitudinal axis of the nucleus. All blocks containing SN were embedded in paraffin wax and sectioned exhaustively with the microtome set to a thickness $(\mathrm{t})$ of $11 \mu \mathrm{m}$. Every 40th section $(\mathrm{m}=40)$ and its neighbour were sampled on separate glass slides, resulting in approximately 15 to 25 section-pairs, and stained with Gallocyaninchromalum. With a random start within the first five section pairs, every fifth section-pair was studied using $20 \mathrm{X}$ objectives in two identical Olympus $\mathrm{BH}-2$ projecting microscopes (see fig 3 in reference 10a). Each of these images were projected side by side onto the table at a final magnification of $320 \mathrm{X}$. With a random start within the first 15 fields of vision, every 15 th of the consecutive fields on each selected section was sampled. Each sample consisted of the counts of all neuronal nuclei within the unbiased sampling frame of area a(frame) $=150 \times 150 \mathrm{~mm}^{2}$. The sampling scheme was designed so that a total number of 75 to 100 pigmented neurons and 75 to 100 non-pig- 
mented neurons were counted. For a complete statistical analysis and a description of the practical details of the stereological procedure, see Pakkenberg and Gundersen."

Only those nerve cell nuclei present in the sampling frame on the first section that were not identified in the paired section were counted. The average number $\bar{Q}^{-}$of nuclei seen in the sampling frame of area a(frame) and not seen in the other section is the number of neurons present in the sample of volume $\overline{\mathrm{t}} \cdot \mathrm{a}$ (frame). The numerical density $\mathrm{N}_{\mathrm{V}}$ in the processed tissue is: $\mathrm{N}_{\mathrm{v}}=\overline{\mathrm{Q}}^{-} /(\overline{\mathrm{t}} \cdot \mathrm{a})$ frame)).

The total volume of the $S \mathrm{~N}$ was estimated with a point counting scheme based on the Cavalieri principle. ${ }^{12}$ The outline of the $S N$ in one section from each of the 15 to 25 sampled pairs was drawn on the coverslip with a thin feltpen. The area of the profile of the $\mathrm{SN}$ was estimated by systematic point-counting at $16 \mathrm{X}$ magnification. An unbiased estimate of the total fixed volume $\mathrm{V}$ of $\mathrm{SN}$ is: $\mathrm{V}(\mathrm{SN})=$ $\mathrm{m} \cdot \overline{\mathrm{t}} \cdot \mathrm{a}(\mathrm{p}) \cdot \Sigma \mathrm{P}$, where $\mathrm{a}(\mathrm{p})$ is the area corresponding to a point in the test system and $\Sigma \mathrm{P}$ is the sum of the points that hit the $\mathrm{SN}$ in one of the two sections of each of the section-pairs. ${ }^{11} 12$ The total number of neurons is: $\mathbf{N}=\mathbf{N}_{\mathrm{v}} \times$ $\mathrm{V}=\mathrm{m} \cdot \overline{\mathrm{t}} \cdot \mathrm{a}(\mathrm{p}) \cdot \Sigma \mathrm{P} \cdot \overline{\mathrm{Q}}^{-} /(\overline{\mathrm{t}} \cdot \mathrm{a}($ frame $))$, an estimator which is independent of the actual section thickness because $\mathbf{N}=\mathrm{m} \cdot \mathrm{a}(\mathrm{p}) \cdot \Sigma \mathbf{P} \cdot \overline{\mathrm{Q}}^{-} / \mathrm{a}$ (frame).

In this study the microtome was set at $11 \mu \mathrm{m}$ but the average section thickness (estimated by focussing from the top to the bottom surface) was $6.3 \mu \mathrm{m}$ with a coefficient of variation, $C V$ $=\mathrm{SD} /$ mean, of $0 \cdot 24$. On average, 150 nerve cell nuclei were counted in 50 fields of vision on three to five systematic section-pairs through the complete $\mathrm{SN}$, a task which took about 60 minutes. Differences between groups were judged by two-tailed Student's paired $t$ test using a significance level of $0 \cdot 05$.

\section{Analysing the sampling procedure}

The estimator of total neuron number used in this study is the product of a "density", " $\mathrm{N}_{\mathrm{v}}$ " $=\Sigma \mathrm{Q}^{-} / \Sigma($ frame $), \mathrm{a}$ "volume", "V" $=\Sigma \mathrm{P}$, and a composite constant $c=m \cdot a(p) / a($ frame) of the sampling scheme: $\mathrm{N}=\Sigma \mathrm{Q}^{-} / \Sigma($ frame $) \cdot \Sigma \mathrm{P} \cdot \mathrm{c}$. The estimator is unbiased because it involves no assumptions about nerve cell sizes, shapes, or shrinkage, and the constant $\mathrm{c}$ is composed of known quantities: two linear magnifications, two self-made test systems, and the fraction $1 / \mathrm{m}$ of all consecutive sections used.

The statistical variation of the estimates, $\mathrm{CE}(\mathrm{N})$, depends to a first approximation on the variation of the density estimate, $\operatorname{CE}\left(\mathrm{N}_{\mathrm{v}}\right)$, and that of the volume, $\mathrm{CE}(\mathrm{V}): \mathrm{CE}(\mathrm{N}) \approx$ $\sqrt{ }\left(\mathrm{CE}^{2}\left(\mathrm{~N}_{\mathrm{V}}\right)+\mathrm{CE}^{2}(\mathrm{~V})\right)$. Due to the precise nature of the Cavalieri-estimate of volume, the coefficient of error CE(V) $=S E M /$ estimate is low $[\mathrm{CE}$ (controls) $=0.05, \mathrm{CE}$ (patients) $=$ 0.04 ], even though the average number of counted points was $\approx 380$.

The average $C E$ of the density estimates taken over $m$ patients $\mathrm{CE}=1 / \mathrm{m} \sqrt{ }\left(\mathrm{CE}_{1}{ }^{2}+\mathrm{CE}_{2}{ }^{2}\right.$ $+\ldots \ldots \mathrm{CE}_{\mathrm{m}}{ }^{2}$ ) was $15 \cdot 6 \%$ for the controls and $17.9 \%$ for the patients with Parkinson's disease. The overall composite $\operatorname{CE}\left(\mathrm{N}_{\mathrm{v}}\right)$ was $\approx$ $17 \%$. Consequently, the statistical variation of the estimate is $\mathrm{CE}(\mathrm{N})=\sqrt{ }\left(17^{2}+3.9^{2}\right) \approx$ $17 \cdot 4 \%$, that is, the $\mathrm{CE}$ of the volume estimate may be neglected. The rather high $\operatorname{CE}\left(\mathrm{N}_{\mathrm{v}}\right)$ is due to the inhomogeneous distribution of neurons in $\mathrm{SN}$ in that they have a tendency to be clustered, but the precision is clearly adequate for the purpose of estimating normal values and demonstrating the defect in patients with Parkinson's disease.

If more subtle changes than those found in this group of long-term patients with Parkinson's disease were to be detected, that would be accomplished by increasing the number of disector samples in each $S N$. If the desired precision $\mathrm{CE}(\mathrm{N})$ of the estimate is $\approx$ $10 \%$, then 140 disectors $\left[(17 \% / 10 \%)^{2} \times 50 \approx\right.$ 140] will suffice. These disectors should preferentially be distributed over a larger number of sections than used in this study to counteract the variation of $\mathrm{CV} \approx 0.25$ in the unknown section thickness.

A close-to-optimal sampling scheme for such studies would then be the following: 1) Make exhaustive sections at a real thickness of $\approx$ $6 \mu \mathrm{m}$ and sample every 80th section; 2) Estimate total $\mathrm{SN}$ area on all sampled sections using a point net of a real density of one point per $16 \mathrm{~mm}^{2}$ (point distance of $4 \mathrm{~mm}$ ); 3) Count $\mathrm{Q}^{-}$in every 15 field of vision at a final magnification of $\approx 250 \mathrm{X}$ using a frame of area $\approx$ $150 \times 150 \mathrm{~mm}^{2}$. If more precision is needed (like in left-right paired studies) sample more sections in step 1 ; if less precision is sufficient (as will be the case in most studies) sample less sections in step 1 . Change only the constants in step 2 and 3 after statistical analysis.

\section{Results}

The total number of pigmented neurons in the two groups in the $\mathrm{SN}$ is shown in fig 1. The

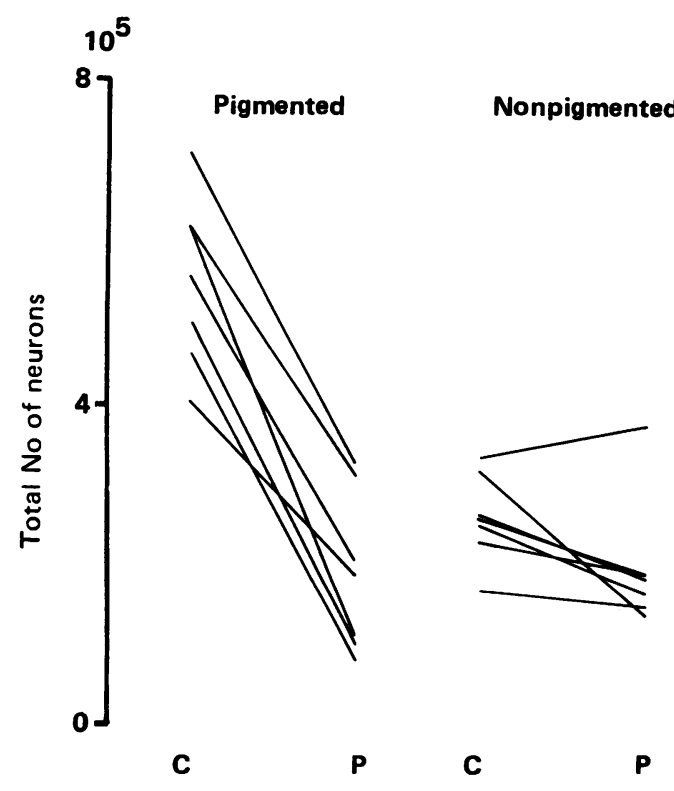

Figure 1. In all cases the total number of pigmented neurons in the substantia nigra from patients with Parkinson's disease was reduced compared with sex-and age-matched controls. 


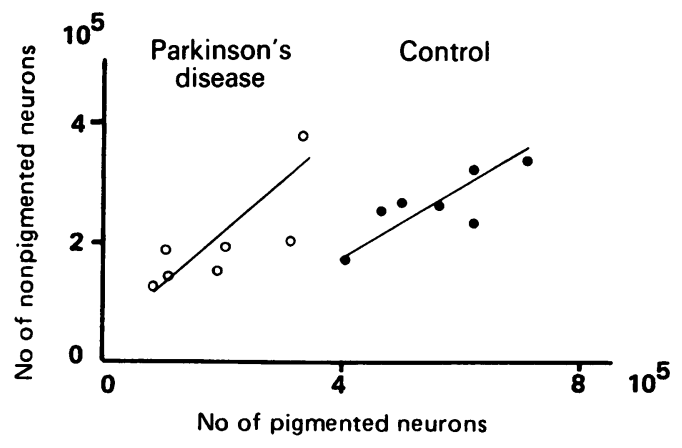

Figure 2 The relationship between the total number of pigmented and non-pigmented neurons in the substantia nigra in control subjects (O) and in patients (O). The major principal axes of the bivariate relationships are shown, the slopes are 0.53 and 0.79 in controls and patients, respectively. The close correlation $(r=0 \cdot 81)$ between the number of pigmented and non-pigmented neurons is statistically significant in controls

$(2 p=0.028)$ whereas in the patients the coefficient of correlation ( $r=0.72)$ just falls short of statistical significance using two-tailed tests $(2 p=0.069)$. Note that there is no overlap between the total number of pigmented neurons in the two groups and that the subject with the highest number of non-pigmented neurons had Parkinson's disease. This might indicate that the primary cell death in substantia nigra is within the group of pigmented neurons while the loss of non-pigmented neurons is a secondary phenomenon.

total number of pigmented cells in the Parkinsonian patients was on the average $1 / 3$ of that in the controls, $2 \mathrm{p}=0.000037$. The total number of non-pigmented neurons in the patients was on the average $3 / 4$ of that in the controls, $2 p=0 \cdot 050$. As shown in fig 2 , in both groups there was a close correlation between the numbers of pigmented and non-pigmented neurons. The correlation in the patients fell just short of statistical significance. The total numbers of neurons showed no relationship to age in either of the two groups (of a rather narrow age range). The patients showed a rather weak tendency to a lower number of pigmented neurons with duration of disease, $r$ $=-0.56,2 \mathrm{p}>0.05$. The mean $(\mathrm{SD})$ volumes of $\mathrm{SN}$ were $512(117) \mathrm{mm}^{3}$ and $390(136) \mathrm{mm}^{3}$ in controls and patients, respectively. The numerical density of pigmented neurons was $1118(274) \mathrm{mm}^{-3}$ in controls and $477(166) \mathrm{mm}^{-3}$ in patients with Parkinson's disease. The corresponding values for non-pigmented neurons were 534 (167) $\mathrm{mm}^{-3}$ and 514 (95) $\mathrm{mm}^{-3}$, respectively.

\section{Discussion}

The substantia nigra in 80 year old humans contains approximately $\mathbf{5 5 0} 000$ pigmented and 250000 non-pigmented neurons with a variation of about $20 \%$. The numbers of the two types of neurons are quite closely related. The total numbers of pigmented and non-pigmented neurons in substantia nigra from seven patients with Parkinson's disease were reduced by $66 \%$ and $24 \%$, respectively, at the time of death. Although nerve cell loss in the $S N$ in normal subjects has been shown earlier to be related to age $^{7}$ this was not the case in our study which comprised small groups of elderly patients. It should be mentioned that estimates of the total number of pigmented and nonpigmented neurons will probably be larger if a magnification higher than $320 \mathrm{X}$, which was applied in this study, is employed. Only neurons with more than 10 to 15 pigmented granules per central profile could be identified as pigmented nerve cells and small non-pigmented neurons were difficult to identify at the relatively low magnification used in this study.

In our study there was a reduction in the neuronal numerical density, and the volume of the $S N$ in the patients was unchanged. These numbers are only reported to provide ideas about the orders of magnitude. The numerous dimensional changes of tissue during the agonal/postmortem phases, during fixation, dehydration, paraffin embedding, sectioning, and so on, make it likely that the estimates do not represent the real values. We may not even make meaningful comparisons between the groups, since it is likely that shrinkage, for example, differs in tissue from normal brains and tissue from severely diseased brains, as discussed in reference 11 .

Some of the patients (five with Parkinson's disease, and two controls) in this series were studied in our laboratory using a conventional, biased counting method some years ago. That study was never completed due to the time needed to count with that technique. This gave us, however, the opportunity to gain some insight into the order of magnitude of the biases in the various commonly used counting methods, see table 2 . If all neurons are counted, for example, on every 40th section and multiplied by 40 to get a "total neuron number", an obvious overestimate is obtained (a fact known since Wicksell's paper written in 1925). ${ }^{13}$ The bias is of the order of 30 to $40 \%$. Proper correction of this overestimation requires information which is difficult to obtain, for example, the real thickness of the section. Furthermore, information is needed which is also unavailable, about the average height of the detectable central part of the neuron nucleus, measured perpendicular to the section plane. A number of correction formulae con-

Table 1 Characteristics of subjects

\begin{tabular}{lllc}
\hline & & Parkinson's disease \\
\cline { 3 - 4 } Sex & Age & Cause of death & $\begin{array}{c}\text { Duration of } \\
\text { disease } \text { (years) }\end{array}$ \\
\hline Male & 69 & coronary occlusion & 7 \\
Female & 73 & pulmonary embolism & 11 \\
Male & 77 & broncho-pneumonia & 16 \\
Female & 80 & pulmonary embolism & 7 \\
Male & 80 & pulmonary embolism & 8 \\
Female & 84 & basilar artery insuf & 4 \\
Female & 86 & broncho-pneumonia & 16 \\
Mean & $78 \cdot 4$ & & $9 \cdot 8$ \\
& & Control group & \\
Male & 71 & coronary occlusion & \\
Female & 71 & coronary occlusion & \\
Male & 75 & coronary occlusion & \\
Female & 81 & pulmonary embolism & \\
Male & 95 & urethral haemorrhage & \\
Female & 86 & coronary occlusion & \\
Female & 87 & coronary occlusion \\
Mean & 82.9 & & \\
\hline
\end{tabular}

The subjects in the two groups were paired according to the sequences shown. 
Table 2 The number, $N$, of pigmented neurons in the SN and the magnification of the bias of various commonly used methods

\begin{tabular}{|c|c|c|c|c|c|c|c|c|c|c|c|}
\hline Sex & Age & $N\left(\times 10^{3}\right)$ & $Q_{A} \times 40$ & $\frac{Q_{A} \times 40}{N}-1 ;$ & $\overline{C B}$ & $\begin{array}{l}\text { Floderus } 1\left(\times 10^{3}\right) \\
d=0.0144, t=0.011\end{array}$ & $\frac{\text { Floderus } 1}{N}-1$ & $\overline{C B}$ & $\begin{array}{l}\text { Floderus } 2\left(\times 10^{3}\right) \\
d=0.0144, t=0.0063\end{array}$ & $\frac{\text { Floderus 2 }}{N}-1$ & $\overline{C B}$ \\
\hline \multicolumn{12}{|l|}{ Control: } \\
\hline Male & 95 & 619 & 1024 & +0.65 & \multirow{2}{*}{+0.38} & 445 & $-0 \cdot 28$ & \multirow{2}{*}{-0.40} & 311 & $-0 \cdot 50$ & \multirow{2}{*}{-0.58} \\
\hline Female & 81 & 709 & 808 & $+0 \cdot 14$ & & 350 & -0.51 & & 245 & -0.65 & \\
\hline \multicolumn{12}{|c|}{ Parkinson's disease } \\
\hline Male & 69 & 112 & 246 & $+1 \cdot 20$ & \multirow{5}{*}{+0.31} & 107 & -0.04 & & 75 & -0.33 & \multirow{5}{*}{-0.42} \\
\hline Female & 84 & 190 & 280 & +0.47 & & 242 & $+0 \cdot 27$ & & 170 & $-0 \cdot 11$ & \\
\hline Female & 80 & 333 & 319 & -0.04 & & 279 & $-0 \cdot 16$ & $-0 \cdot 16$ & 194 & -0.42 & \\
\hline Female & 73 & 207 & 280 & +0.35 & & 121 & -0.42 & & 85 & -0.59 & \\
\hline Male & 77 & 103 & 110 & +0.07 & & 48 & -0.53 & & 33 & -0.68 & \\
\hline
\end{tabular}

In Floderus 1 the nominal section thickness of $11 \mu \mathrm{m}$ is used, in Floderus 2 the actual mean thickness of $6.3 \mu \mathrm{m}$ is used. Note that the average coefficient of bias, $\overline{\mathrm{CB}}$, is not the mean of individual estimates of the bias but is calculated from the averages of the estimates in the controls and the patients, respectively; $d$ is the mean diameter of pigmented neuronal profiles in which a nucleolus could be identified.

taining further assumptions have been developed to reduce these biases. An often used correction formula of this kind is from Floderus ${ }^{14}: \mathrm{N}_{\mathrm{V}}=\mathrm{Q}_{\mathrm{A}} /(\mathrm{t}+\mathrm{d}-2 \mathrm{k})$, where $\mathrm{N}_{\mathrm{V}}$ is numerical density, $Q_{A}$ number of objects actually counted per area, $t$ the (approximate) nominal section thickness, $d$ the (approximate) mean diameter of the particles counted and $k$ the (approximate) correction-factor for the size of invisible or lost caps. In our biased study, for comparison purposes, the net sum of biases, using Floderus' correction formula and the nominal section thickness of $11 \mu \mathrm{m}$ (to which we set our microtome), resulted in an underestimation of the order of -20 to $-40 \%$. This situation could not be remedied by using the actual rather than the nominal section thickness, the bias actually reached from -40 to $-60 \%$.

Through the history of cell counting only those studies which have estimated total numbers based on both density and the total volume of the processed examined tissue have a chance of escaping the "reference trap" from which no conclusions can be drawn. ${ }^{15}$ The stereological method reported here is free of any assumptions about nerve cell size, section thickness and of dimensional changes of brain tissue induced by histological procedures and thus presents an unbiased estimate of total neuron number. Furthermore, it is also highly efficient since the total neuron number was estimated within one hour compared with the counting effort of three to four weeks using previously biased methods.

The authors wish to acknowledge the support provided by The
Danish Medical Research Council (FTU-project), The Lundbeck Foundation, The Danish Parkinson Association, Mark J assistance by Elisabeth Kabell-Kjær and Anette Funder.

1 Trétiakoff, C. Contribution a l'étude de l'anatomie pathologique du locus niger de saemmering avec quelque deductions relatives a la pathogénie des troubles du tonus musculaire et de la maladie de Parkinson. These pour le doctorat en Medicine. Paris: 1919, 1-24.

2 Foix MC. Les lésions anatomiques de la maladie de Parkinson. Revue Neurologique 1921;38:593-600.

3 Hassler R. Zur Pathologie der Paralysis Agitans und des Postenzephalitischen Parkinsonismus. J Psychol Neurol 1938;48:387-476.

4 Greenfield JG. Neuropathology, 4th ed. In: Hume Adams J, Corsellis JAN, Duchen LW, eds. London: Edward Arnold, 1984:1-1126.

5 Weil A. Text book of neuropathology. London: W Heinemann, 1946.

6 Pakkenberg $\mathrm{H}$, Brody $\mathrm{H}$. The number of nerve cells in the substantia nigra in paralysis agitans. Acta Neuropath 1965;5:320-4.

7 McGeer PL, McGeer EG, Suzuki JS. Aging and extrapyramidal function. Arch Neurol 1977;34:33-5.

8 Langston JW. MPTP and Parkinson's disease. Trends in Neurosci 1985;80:79-83.

9 Sterio DC. The unbiased estimation of number and sizes of arbitrary particles using the disector. J Microsc 1984; 134:127-34.

10a Gundersen HJG, Bendtsen TF, Korbo L, et al. Some new, simple and efficient stereological methods and their use in pathological research and diagnosis. Review article. APMIS, 1988;96:379-94.

$10 \mathrm{~b}$ Gundersen HJG, Bagger P, Bendtsen TF, et al. The new stereological tools: disector, fractionator, nucleator and point sampled intercepts and their use in pathological research and diagnosis. APMIS 1988;96:857-81.

11 Pakkenberg B, Gundersen HJG. Total number of neurons and glial cells in human brain nuclei estimated by the disector and the fractionator. J Microsc 1988;150:1-20.

12 Gundersen HJG, Jensen EB. The efficiency of systematic sampling in stereology and its prediction. J Microsc sampling in ster

13 Wicksell SD. The corpuscle problem. Biometrica 1925; 17:84-99.

14 Floderus S. Untersuchungen über den Bau der menschlichen Hypophyse mit besonderer Berücksichtigung der quantitativen mikromorphologischen Verhältnisse. Acta Pathol Microbiol Scand 1944:(Suppl 53).

15 Brændgaard H, Gundersen HJG. Recent stereological developments in neuroscience. $J$ Neurosci Meth 1986; 18:39-78. 